\title{
EXPERIÊNCIA DE CONSUMO E O PAPEL DA QUALIDADE DO SERVIÇO EM CONCESSIONÁRIAS DE VEÍCULOS
}

\section{CONSUMER EXPERIENCE AND THE ROLE OF SERVICE QUALITY IN AUTOMOBILE RETAILS}

Ieda Pelogia Martins Damian

Doutora em Administração de Organizações

pela FEA-RP/USP;

Docente da Universidade de São Paulo

ieda.martins@bol.com.br

\section{Edgard Monforte Merlo}

Doutor em Administração pela

Universidade de São Paulo;

Professor Associado da FEA-RP/USP

edgardmm@usp.br

\author{
Contextus \\ ISSNe 2178-9258 \\ Organização: Comitê Científico Interinstitucional \\ Editor Científico: Marcelle Colares Oliveira \\ Avaliação : Double Blind Review pelo SEER/OJS \\ Revisão: Gramatical, normativa e de formatação \\ Recebido em 23/09/2011 \\ Aceito em 06/03/2014 \\ $3^{\mathrm{a}}$. versão aceita em 17/03/2014
}

\section{RESUMO}

Compreender a influência da experiência do consumo, suas relações com a qualidade do serviço e suas implicações para os gestores podem ser consideradas contribuições relevantes. A importância do setor automotivo e dos relacionamentos entre os conceitos acima levou ao objetivo deste trabalho, que foi analisar o papel da experiência de consumo e da qualidade dos serviços automotivos. Foi aplicado um questionário, enviado a cerca de 10.000 e-mails em território nacional, e foram obtidas 444 respostas válidas. Os resultados demonstraram que os aspectos relacionados à qualidade do serviço foram considerados tão importantes quanto os elementos relacionados à experiência de consumo. Os aspectos da experiência de consumo mais destacados pelos consumidores dizem respeito ao prazer da compra, ao sortimento e aos preços. Em relação à qualidade dos serviços, os elementos em destaque estavam vinculados a serviços de alta qualidade, atendimento dos funcionários, tempo de atendimento $\mathrm{e}$ cumprimento de prazos.

Palavras-chave: Experiência de consumo. Qualidade do serviço. Concessionária de veículos.

\begin{abstract}
To understand the influence of the consumption experience, their relationships with service quality and its implications for managers can be considered important contributions. The importance of the automotive sector and the relationships between the above concepts led to the goal of this study that was to examine the role of the consumer experience and the quality of automotive service. It was applied a questionnaire sent to 10,000 emails across the country and 444 valid responses were obtained. The results showed that the aspects related to service quality were considered as important as the elements related to the consumption experience. Aspects of the leading consumer experience by consumers relate to the pleasure of buying, assortment and prices. Regarding quality of services, the highlighted elements were related to high quality services, care of employees, attendance time and meeting deadlines.
\end{abstract}

Keywords: Consumer experience. Service quality. Automobile retails. 


\section{INTRODUÇÃO}

O setor automotivo no Brasil, de acordo com os dados do Banco Nacional de Desenvolvimento Social e Econômico (BNDES, 2008), desempenhou um papel de grande importância na história recente da indústria nacional, principalmente no início da década de 90, quando o setor foi emblemático no processo de abertura comercial e de modernização da indústria. Em 1995, quando o governo anunciou um conjunto de medidas e incentivos direcionados ao segmento, o Regime Automotivo, iniciou-se um ciclo de grandes investimentos para o setor. $\mathrm{O}$ Brasil ocupa lugar de destaque no cenário mundial quando se fala em setor automotivo: está em ascensão tanto no ranking de maiores mercados quanto no de maiores produtores de veículos, configurando-se como um importante player mundial.

Esse novo cenário, que sinalizava a prospecção de um grande número de novos consumidores de serviços automotivos, despertou nas concessionárias de veículos o desejo de aumentar suas carteiras de clientes. Nunes e Martins (2013) destacaram que o surgimento de consumidores mais exigentes e o crescimento da demanda interna de veículos contribuíram fortemente para o crescimento da disputa pelas concessionárias.

Analisando o mesmo aspecto por outro prisma, Pimenta e Cruz (2014) ressaltaram que as mudanças na conjuntura econômica mundial, combinadas com mais opções de marcas e modelos no setor de distribuição de automóveis no Brasil, promoveram uma intensa concorrência no setor automotivo e uma redução drástica na taxa de lucro da rede de concessionárias autorizadas, modificando o paradigma tradicional dessas organizações.

Abrangendo as duas observações, pode-se afirmar que nesse cenário, com consumidores mais exigentes, a oferta de uma experiência de consumo que deixe os consumidores satisfeitos pode ser um aspecto na escolha de um serviço. A experiência de consumo relacionada ao serviço que lhes foi oferecido vem ocupando cada vez destaque tanto na área empresarial quanto na área acadêmica.

Apesar de existir um grande número de estudos que demonstram a importância da experiência de consumo e da qualidade do serviço, como as contribuições de Bäckström e Johansson (2006), Berry (2009), Bitran, Ferrer, Oliveira (2008), Cronin, Brady e Hult (2000), Cronin e Taylor (1994), Gentile, Spiller e Noci (2007), Grewal, Levy e Kumar (2009), Jonhson, Tsiros e Lancioni 
(1995), Palmer (2010), Parasuraman, Zeithaml e Berry (1985), Puccinelli et al. (2009), Verhoef et al. (2009), Zeithaml (2000), poucos estudos foram encontrados sobre a efetiva relação entre esses conceitos. A carência de estudos se torna ainda maior quando se enfoca a área de serviços em concessionárias de veículos, apesar de sua importância tanto em âmbito nacional quanto internacional. Essa escassez de pesquisas justifica o propósito deste estudo, que foi o de avaliar a experiência de consumo e o papel da qualidade do serviço em concessionárias de veículos.

Com o intuito de alcançar os objetivos propostos, foi construído um questionário cujas afirmações foram adaptadas às características específicas desta investigação. As afirmações relativas à experiência de consumo foram baseadas em Verhoef et al. (2009) e Bäckström e Johansson (2006), e as afirmações relacionadas à qualidade do serviço foram baseadas na literatura de Parasuraman, Zeithaml e Berry (1985), compondo um questionário original por abarcar dois aspectos de grande importância e que ainda não haviam aparecido de forma combinada na literatura acadêmica. Por meio dos resultados obtidos, esta pesquisa pretende contribuir tanto para o setor varejista como para os pesquisadores dessa área, uma vez que este assunto é de interesse crescente devido aos benefícios diretos a ele associados. Além disso, este estudo pretende contribuir para despertar o interesse para uma área que ainda carece de estudos.

\section{REFERENCIAL TEÓRICO}

\subsection{Experiência de Consumo}

O conceito de Customer Experience foi concebido em meados da década de 1980 como uma visão inovadora para o estudo do comportamento do consumidor. O ponto de partida foi uma nova maneira de considerar o estudo do processo de consumo. De acordo com esse ponto de vista, esse processo pode ser considerado uma experiência abrangente que envolve uma pessoa - ao contrário de um cliente como um todo em diferentes níveis e em todas as interações entre essa pessoa e uma empresa, ou uma oferta da empresa. O que contribui para a criação de valor não é tanto vender experiências memoráveis, mas permitir que o cliente vivencie todos os momentos da relação com uma empresa de uma maneira excelente, de modo que essa experiência supere suas expectativas (GENTILE, SPILLER e NOCI, 2007).

A experiência do cliente, de acordo com os autores acima citados, é originária de um conjunto de interações entre $o$ cliente e o produto, a empresa, ou parte da 
organização, que provocam uma reação, sendo a experiência estritamente pessoal, o que implica o envolvimento do cliente em diferentes níveis: racional, emocional, sensorial, físico e espiritual.

Para compreender as experiências de consumo, Puccinelli et al. (2009) afirmaram a necessidade de entender que os consumidores tentam alcançar alguma meta através da compra, usando um determinado produto ou serviço e que, independentemente dos objetivos específicos, eles estabelecem uma progressão da experiência, uma percepção do ambiente de varejo, e constroem sua satisfação com a experiência. $\mathrm{O}$ mesmo ambiente de varejo, acrescentaram os autores, pode produzir muitos resultados e sentimentos diferentes, dependendo dos objetivos do consumidor, que também podem variar em função da ocasião da compra.

As experiências de consumo são, de acordo com Pine II (2010), situações únicas, em que os clientes não devem ser considerados como mercados, mas sim sob uma perspectiva individual, uma vez que a experiência é única e tem potencial para modificar os clientes como seres humanos. As experiências, continua o autor, devem, em primeiro lugar, se concentrar no sacrifício do cliente, ou seja, na brecha do que ele realmente necessita e no que a empresa pode oferecer. Em segundo lugar, a empresa deve se preocupar em surpreender o cliente, isto é, deixar de lado a noção de satisfazer as expectativas e passar para uma dimensão totalmente inesperada.

Berry (2009) argumentou que os consumidores podem tolerar variações nas suas experiências e, ainda assim, as considerar aceitáveis devido à existência de uma "zona de tolerância", indicativa de que os consumidores não esperam um serviço em um determinado nível; em vez disso, eles aceitam um nível adequado para o serviço, mas, se esse nível vai além do desejado, o serviço pode gerar uma resposta mais positiva por parte do consumidor.

Bäckström e Johansson (2006) realizaram pesquisas para analisar como varejistas e consumidores se relacionam com experiências de consumo no interior da loja. Apontaram o uso de técnicas varejistas cada vez mais avançadas a fim de criar experiências para seus consumidores, em contraste com a descrição dada pelos consumidores, que revelou que as suas experiências na loja são, na grande maioria, constituídas por valores tradicionais, tais como comportamento dos funcionários, seleção satisfatória dos produtos e um layout que facilite a visita à loja. Os autores ressaltaram que: (1) é evidente que a interação entre funcionários $\mathrm{e}$ 
consumidores é crucial na maneira como os consumidores percebem os encontros de serviço, além da capacidade desses funcionários de fornecer conselhos úteis, dar sugestões sobre o que poderia atender o consumidor ou tratar reclamações; (2) os preços também contribuem para a criação da experiência dos consumidores na loja; (3) o aspecto do tempo indica que as lojas que conseguem oferecer um serviço rápido podem ter sucesso em atrair consumidores orientados para a tarefa e contribuir para uma experiência positiva.

Ao realizar um estudo que se propunha avaliar criticamente a validade conceitual da experiência do cliente de como construir e propor um modelo que integra os relacionamentos interpessoais, qualidade de serviço e marcas, Palmer (2010) observou que muitas empresas viram a gestão da experiência do cliente (CEM, sigla inglesa) como um sucessor da gestão de relacionamento com o cliente (CRM): o gerenciamento da experiência de consumo pode ser um quadro que integra e supera as limitações teóricas e práticas do CRM.

No contexto do varejo, segundo Bäckström e Johansson (2006), os benefícios extrínsecos da experiência de consumo normalmente decorrem de compras que são utilitaristas, e o valor intrínseco pode ser obtido a partir da apreciação de uma experiência para o próprio bem do cliente, independentemente do resultado.

De acordo com a pesquisa realizada pelos autores acima citados, a maioria dos varejistas concorda que parece haver um aumento da procura de experiências de consumo e que é crucial focar em melhorar essas vivências na loja, razão pela qual os varejistas têm dedicado recursos consideráveis para implementar técnicas cada vez mais avançadas para criar experiências excitantes. Por outro lado, para os consumidores, pequenas coisas criam experiências, como por exemplo, um sorriso ao entrar numa loja ou o fato de os funcionários demonstrarem interesse pelos clientes na loja. Dessa maneira, os autores sugeriram que educar e motivar o pessoal da loja para abordar os consumidores de forma satisfatória é uma questão central para o varejo no futuro, além de outras questões fundamentais, como a limpeza e o layout de loja.

$$
\text { Reforçando os benefícios da }
$$
experiência de consumo, Pine II (2010) afirmou que à medida que os serviços se tornam commodities, as empresas podem alcançar outro patamar de mercado se oferecer experiências a seus clientes. Segundo o autor, a experiência de consumo é o único caminho que os varejistas possuem para evitarem a "commoditização". 
Verhoef et al. (2009) ressaltaram que, apesar dos benefícios advindos da experiência do cliente, proporcionar um valor superior ao cliente pode ser bastante caro. Nesse sentido, é preciso verificar se os clientes querem pagar mais por uma experiência enriquecida. Os autores concluíram que pesquisas sobre a experiência dos clientes são limitadas, apesar do reconhecimento da importância dessa experiência, explorada em profundidade apenas por um pequeno número de artigos, a partir de uma perspectiva teórica.

Palmer (2010) reforçou que o conceito de experiência de consumo apresenta ambiguidades e desafios para os gestores e acadêmicos, em que a falta de uma resposta erudita e previsível implica a experiência como um fenômeno transitório, isto é, uma experiência específica é incapaz de dar uma vantagem competitiva porque, no próximo encontro, algumas das suas novidades terão perdido o valor. Assim, é mais adequado que os gerentes pensem em um fluxo de experiências desenvolvidas ao longo do tempo para alcançar uma vantagem competitiva sustentável.

Os varejistas, de acordo com o autor acima citado, enfrentam os seguintes desafios em relação à experiência de consumo: (1) o desenvolvimento de uma escala de medida para a experiência do cliente porque uma medida operacionalmente aceitável precisaria englobar a complexidade das variáveis de um contexto específico; (2) a nãolinearidade da experiência do cliente; (3) a identificação de um nível ótimo de experiência.

Verhoef et al. (2009) propuseram um modelo conceitual dos antecedentes e dos moderadores da experiência de consumo, em que ressaltam a importância de compreender que o processo de criação da experiência do cliente é composto de múltiplos pontos de contato independentes durante o processo de troca. O modelo em questão está representado na Figura 1. 
Figura 1 - Modelo conceitual da criação da experiência de consumo

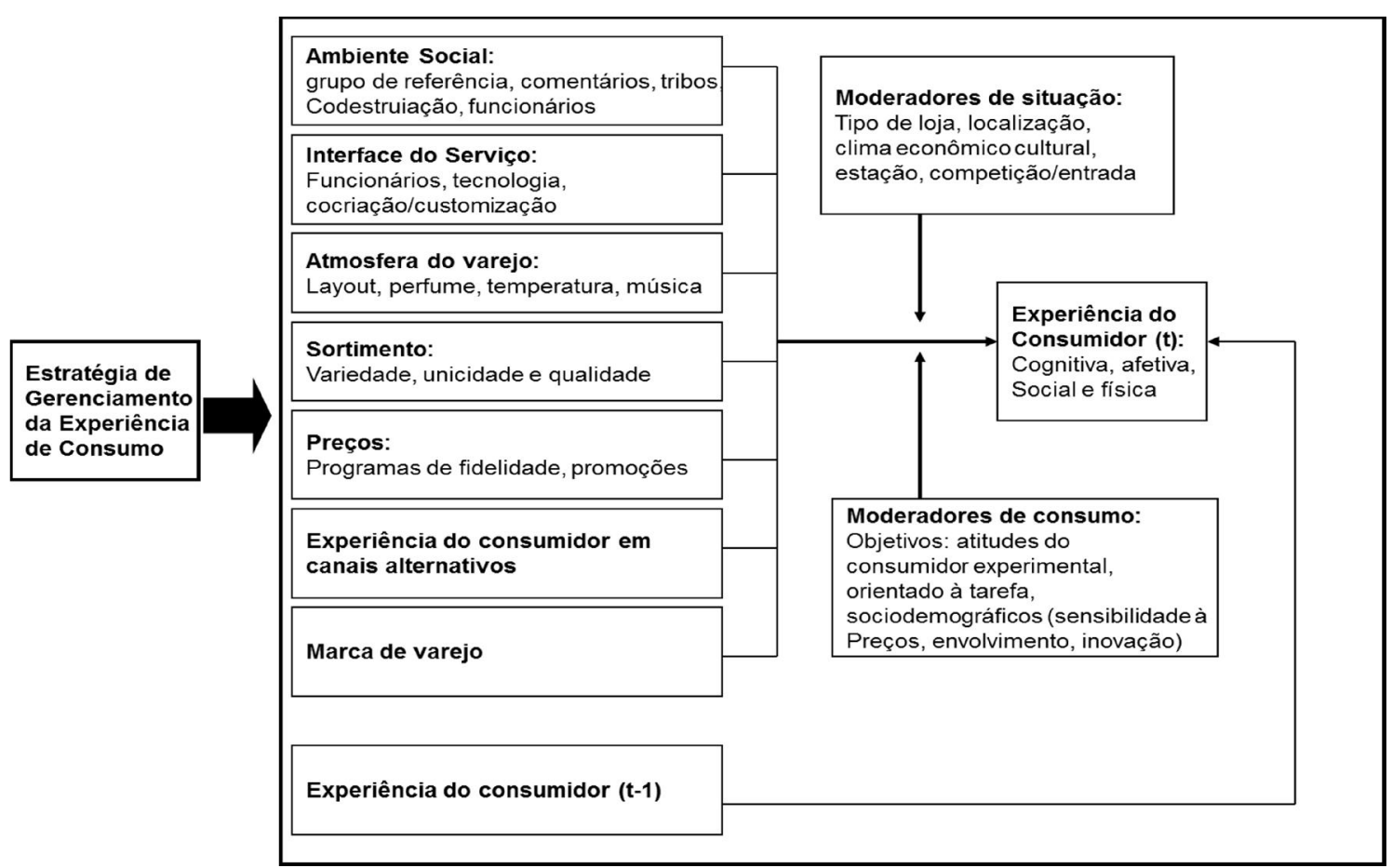

Fonte: Verhoef et al. (2009).

Esse modelo conceitual foi utilizado nesta pesquisa pelo fato de incorporar os múltiplos elementos da experiência de consumo. Entretanto, nesse modelo, o elemento qualidade dos serviços ainda é pouco explorado, ficando restrito ao atributo sortimento. Por esse motivo, foi empregado o modelo de experiência de consumo proposto acima com a incorporação de aspectos existentes na ferramenta Servqual ampliado que será explicada adiante, podendo ser considerada uma abordagem sistêmica do problema de qualidade do serviço, que se enquadra na literatura de experiência de consumo.

O próximo item deste estudo discorre sobre conceitos e assuntos relevantes relacionados à qualidade dos serviços, devido ao papel que ela, juntamente com a experiência de consumo, desempenha nesta pesquisa.

\subsection{Qualidade em Serviços}

Em seu estudo sobre qualidade, Shewhart $\left(1931^{1}\right)$ apud Chen e Ting (2002) sugeriu que a qualidade poderia ser dividida em qualidade objetiva e qualidade subjetiva: a primeira não tem nenhuma relação com pessoas, mas sim com o produto; já a segunda é a maneira pela qual os consumidores percebem a qualidade objetiva. Assim, diferentes consumidores, complementam Chen e Ting (2002), não 
teriam necessariamente a mesma percepção de qualidade subjetiva para os produtos com as mesmas qualidades objetivas, o que mostra que a qualidade está conectada com o consumidor.

Outra forma de divisão da qualidade de serviços foi proposta por Grönroos (1998) que, ao formular o modelo da qualidade percebida do serviço, verificou que essa qualidade poderia ser dividida em dois tipos: qualidade técnica e qualidade funcional.

Para que as empresas possam usufruir os benefícios trazidos pela qualidade, é preciso levar em consideração as diferenças entre produtos e serviços que influenciam na avaliação de qualidade do serviço. Essas diferenças são significativas e causam impactos não só na avaliação da qualidade do serviço, mas também na maneira mais adequada de medir esse tipo de qualidade.

As pesquisas realizadas por Parasuraman, Zeithaml e Berry (1985) indicaram que os consumidores basicamente usam critérios similares para avaliar a qualidade do serviço, critérios esses alocados em dez categorias denominadas "determinantes da qualidade do serviço", a saber: confiabilidade, responsabilidade, acesso, cortesia, comunicação, credibilidade, segurança, entendimento/conhecimento do cliente e tangibilidade.
As características específicas dos serviços em relação aos produtos que podem dificultar a sua medição, exigindo instrumentos específicos para tal fim, foram relatadas por Jonhson, Tsiros e Lancioni (1995): a intangibilidade dos serviços pode causar dificuldades de medição, e muitos fatores afetam a percepção do indivíduo sobre a qualidade do serviço. Os autores relataram que as primeiras tentativas para medir a qualidade de serviço utilizaram as medidas modeladas pelas indústrias de produtos e, assim, acabaram focando principalmente o resultado final, negligenciando, dessa forma, os componentes dos serviços que possuem importantes parcelas sobre $\mathrm{o}$ resultado final. A sugestão dos autores para a compreensão do ponto de vista dos consumidores em relação ao nível de qualidade foi considerar as percepções dos serviços de entrada, os processos de serviço e as percepções do serviço resultante.

Fitzsimmons e Fitzsimmons (2000) e Lovelock (2004) indicam que existe uma grande dificuldade de medir a qualidade dos serviços que, ao contrário de um produto com características físicas que podem ser objetivamente mensuradas, contém muitas características psicológicas que frequentemente se estendem além do encontro imediato, porque tem um impacto 
sobre a qualidade de vida futura de uma pessoa.

Apesar de todas as dificuldades relacionadas à mensuração da qualidade do serviço, Cronin e Taylor (1994) e Zeithaml (2000) reforçaram a importância dessa medição, uma vez que a qualidade do serviço pode levar a uma série de relevantes benefícios.

De acordo com o estudo realizado por Cronin, Brady e Hult (2000), os consumidores de serviços mostraram dar mais importância à qualidade do serviço do que aos custos associados com a sua aquisição. Corroborando essa visão, Lovelock (2004) e Berry (2009) afirmam que, para surpreender e entusiasmar os clientes, a qualidade deve estar acima do nível desejado, o que se considera como qualidade superior.

Uma das ferramentas mais utilizadas para mensurar a qualidade dos serviços é a técnica Servqual que, segundo Tan e Pawitra (2001), pode ser descrita como um instrumento de diagnóstico para descobrir amplas áreas de forças e fracassos na qualidade de serviço de uma organização.

Ladhari (2009) realizou um extenso trabalho em que revisou 20 anos (19882008) de pesquisas sobre a escala Servqual para medir a qualidade do serviço. Identificou e resumiu numerosas críticas teóricas e empíricas da escala baseadas em uma seleção de 30 aplicações, concluindo que essa ferramenta continua sendo um instrumento útil para a pesquisa de qualidade de serviços - aspecto também ressaltado por Finn e Kayande (2004) e Grönroos (1998).

Corroborando com o autor acima, Yan e McLaren (2010) utilizaram o modelo Servqual para calcular a distância entre as expectativas dos clientes e as percepções dos funcionários de uma concessionária de veículos e concluíram que essa ferramenta é um meio simples e barato de avaliação de qualidade de serviços.

A partir das diversas contribuições e críticas ao método Servqual, Jonhson, Tsiros e Lancioni (1995) propuseram a criação do Servqual ampliado, que considera as percepções dos serviços de entrada, os processos de serviço e as percepções do serviço resultante, levando em consideração as características específicas dos serviços que os fariam diferentes dos produtos e que afetariam a percepção de qualidade deles.

Para o questionário utilizado neste estudo, foram considerados os aspectos que compõem o Servqual ampliado, proposto por Jonhson, Tsiros e Lancioni (1995), uma vez que o método leva em consideração todas as etapas da teoria de 
sistemas. Além das afirmações contidas no Servqual ampliado, outras foram incluídas no questionário para que os elementos da experiência de consumo pudessem ser avaliados.

No próximo tópico é apresentado o ambiente de serviços das concessionárias automotivas no Brasil, de modo a posicionar o leitor sobre os cenários e as influências do macroambiente na experiência de consumo.

\subsection{Serviços nas concessionárias automotivas brasileiras}

O varejo, de acordo com Parente (2000), consiste em todas as atividades que englobam o processo de venda de produtos e serviços para atender a uma necessidade pessoal do consumidor final.

A função varejista de fornecer serviços é de especial interesse neste estudo, uma vez que ele se propõe a analisar a importância de fatores como experiência de consumo e qualidade dos serviços, mais especificamente os serviços de concessionárias automotivas.

Os serviços, segundo Vargo e Lusch (2004), podem ser definidos como a aplicação de competências especializadas (conhecimentos e competências) através de atos, processos e desempenhos para o benefício de outra entidade ou da própria entidade. Em geral, ainda de acordo com esses autores, os consumidores não precisam somente de mercadorias, mas também de serviços que satisfaçam as suas necessidades.

Em relação aos serviços, Torres Jr., Miyake e Pereira (2006) realizaram um estudo em que demonstraram a importância do desenvolvimento de serviços para as organizações e ressaltaram que, apesar da relevância do tema, esse aspecto permanece ainda pouco estudado na literatura de gerenciamento de serviços. Essa afirmação justifica este estudo, que enfoca a área de serviços ao pesquisar os elementos da experiência de consumo e da qualidade dos serviços automotivos em concessionárias de veículos.

Corroborando com os autores acima citados, Berry (2009) ressaltou que o serviço cria valor para os clientes e valor superior, sendo a melhor maneira de concorrer a qualquer momento e a única em momentos de recessão. Um valor superior implica a maximização dos benefícios e a redução dos encargos para os clientes. Superar as expectativas dos clientes é a essência da qualidade do serviço. A avaliação dos clientes sobre a qualidade do serviço é uma avaliação cumulativa, uma vez que cada nova experiência com a organização combina com experiências passadas.

Nos casos dos serviços de assistência técnica oferecidos pelas 
concessionárias, mais especificamente, Pieritz (2003) relatou duas situações distintas: (1) quando os serviços são em garantia, nesse caso pagos pela montadora, e o preço é determinado por ela mesma, sem a participação da concessionária, sendo o cliente apenas atendido pela concessionária; (2) quando os serviços são de manutenção, fora de garantia, em que os preços são estabelecidos pela concessionária e pagos pelo cliente que, nesse caso, é realmente um cliente da concessionária.

De acordo com o grau de intensidade de trabalho e o de interação e customização, os serviços podem receber diferentes classificações. Segundo Lambin (2000), as assistências técnicas oferecidas pelas concessionárias podem ser consideradas como lojas de serviços, porque as interações e as customizações são relativamente baixas, mas com alta intensidade de trabalho.

A Associação Nacional dos Fabricantes de Veículos Automotores (Anfavea, 2009), ao abordar especificamente a questão dos serviços automotivos no Brasil, afirmou que esse segmento impulsionou o Brasil a mudar de patamar econômico. De acordo com a Federação Nacional da Distribuição de Veículos Automotores (Fenabrave, 2008), o crescimento do setor se deu devido à continuidade das facilidades de crédito, com diminuição da taxa de juros e, principalmente, devido ao aumento dos prazos de pagamento. Adicionalmente, foi mencionado o elevado crescimento da massa real de renda e do emprego, ocorrido a partir de 2004 com o crescimento do PIB e a redução do desemprego na economia brasileira.

No Brasil, segundo Popadiuk e Meinert (2007), as montadoras optaram por seguir o modelo convencional americano de se utilizarem empresários locais para fazer a venda e a assistência técnica nos veículos por elas fabricados. Tais empresários têm contratos de concessão com as montadoras, obtendo a exclusividade da representação da marca em um território predefinido; assumem a responsabilidade de fazer a venda dos veículos novos, de prestar serviços de assistência técnica e de fornecer peças originais de fábrica.

De acordo com Beber e Rossi (2006), as concessionárias normalmente dispõem de boa estrutura para prestação de serviços, sendo responsáveis pela execução dos trabalhos referentes às garantias dos fabricantes para os produtos novos.

\section{MÉTODO DE PESQUISA}

\subsection{Amostragem e análise dos resultados obtidos}


A presente pesquisa foi desenvolvida por meio de um pré-teste, seguido de uma pesquisa quantitativa que utilizou questões fechadas, usando a escala Likert de cinco pontos, (em que 5 relacionava-se à opção "concordo totalmente" e 1 à escolha "discordo totalmente") com amostragem por conveniência com consumidores de serviços automotivos em concessionárias.

Foi realizado um pré-teste com cerca de 60 questionários e foram identificadas as questões que poderiam apresentar problemas de compreensão, e, após o pré-teste, uma questão reconhecida como ambígua foi retirada.

$\mathrm{Na}$ pesquisa quantitativa, os dados foram coletados por meio de questionários respondidos por usuários de serviços automotivos em concessionárias. O convite para responder o questionário foi desenvolvido e enviado pela internet para cerca de 10.000 e-mails em todo o território nacional, obtendo 444 respostas válidas, ou seja, 4,44\% dos e-mails enviados retornaram preenchidos de modo correto.

A primeira parte do questionário foi construída com o objetivo de caracterizar o entrevistado, através de questões que permitiram classificá-lo por faixa etária, sexo, estado e grau de escolaridade.

A segunda parte do questionário foi composta por 25 afirmações, que se propunham a avaliar a influência dos elementos da experiência de consumo e dos atributos da qualidade do serviço na satisfação dos consumidores de serviços automotivos em concessionárias. Entre essas afirmações, 11 estavam relacionadas à experiência de consumo, descritas no Quadro 1.

Quadro 1 - Afirmativas relacionadas à experiência de consumo
\begin{tabular}{|l|l|}
\hline Questão & Afirmativas relacionadas à experiência de consumo \\
\hline 1 & Os produtos eram de boa qualidade \\
\hline 3 & A empresa possuía boa localização \\
\hline 6 & Os funcionários pareciam felizes com o serviço \\
\hline 15 & Os preços eram muito bons \\
\hline 16 & As promoções eram muito boas \\
\hline 17 & As opções de produtos eram muito boas \\
\hline 18 & O ambiente da loja era agradável \\
\hline 19 & Eu gostei de comprar nessa loja \\
\hline 20 & Eu considero esta empresa muito confiável \\
\hline 22 & Eu considero que a imagem desta empresa é muito boa \\
\hline 24 & A empresa ofereceu facilidades de pagamento \\
\hline
\end{tabular}


Além das afirmações acima consumidores. $\mathrm{O}$ Quadro 2 traz as mencionadas, 13 foram elaboradas com a finalidade de verificar os atributos da afirmações relacionadas à qualidade dos qualidade dos serviços na satisfação desses serviços.

Quadro 2 - Afirmativas relacionadas à qualidade dos serviços
\begin{tabular}{|l|l|}
\hline Questão & Afirmativas relacionadas à qualidade dos serviços \\
\hline 2 & A empresa possuía equipamentos modernos \\
\hline 4 & As instalações físicas eram visualmente atraentes \\
\hline 5 & Os funcionários foram gentis \\
\hline 7 & Os funcionários responderam as perguntas com clareza \\
\hline 8 & Os funcionários prestaram atenção às minhas necessidades \\
\hline 9 & A empresa entregou os serviços no prazo prometido \\
\hline 10 & A empresa oferecia um horário de atendimento adequado \\
\hline 11 & Eu recebi o serviço que esperava \\
\hline 12 & O serviço foi feito corretamente da primeira vez \\
\hline 13 & A empresa ofereceu um serviço confiável \\
\hline 14 & O desempenho do serviço foi variável \\
\hline 21 & Eu considero os serviços desta empresa de alta qualidade \\
\hline 23 & O atendimento foi rápido \\
\hline
\end{tabular}

Fonte: elaborado pelos autores.

A última afirmação que compunha essa segunda parte do questionário dizia respeito a uma avaliação da satisfação global em relação ao serviço automotivo realizado na concessionária: "Minha satisfação global é (dê nota de 1 a 5)".

O conceito de satisfação de cliente foi introduzido por Cardoso $(1965)^{2}$ apud Chen e Ting (2002) e desde então tem tido diferentes definições - umas relacionadas ao grau de realização dos benefícios dos produtos que os consumidores esperam, e outras mais focadas na comparação de recompensas dos resultados esperados com o custo do investimento.
A satisfação, para Parker e Mathews (2001), pode ser vista como o resultado de uma experiência ou como um processo, e se complementa com uma outra abordagem que se refere à satisfação como uma atitude. As variáveis-chave que afetam a satisfação do consumidor, de acordo com a pesquisa do citado autor são: expectativas, desconformidades, desempenho percebido e atitudes prioritárias.

Todas as 25 afirmações foram baseadas em importantes estudos, entre os quais devem-se destacar Jonhson, Tsiros e Lancioni (1995), Parasuraman, Zeithaml e 
Berry (1985), Verhoef et al. (2009) e Bäckström e Johansson (2006).

Os seguintes aspectos que compõem a experiência de consumo não foram considerados: (1) ambiente social, porque a escolha de serviços automotivos não sofre uma influência direta de grupos sociais de referência (como em outras atividades de varejo de consumo); (2) marca, considerada no momento da aquisição do veículo, e não no consumo de serviços automotivos.

O questionário foi analisado utilizando-se de técnicas de regressão linear múltipla, visando identificar quais os elementos da experiência de consumo e da qualidade dos serviços automotivos que apresentavam maior influência na construção da satisfação global dos consumidores.

\subsection{Participantes}

Utilizou-se, primeiramente, uma análise descritiva da amostra com o objetivo de obter o perfil dessa amostra e, depois, a análise de regressão múltipla, técnica estatística que pode ser usada para analisar a relação entre uma variável, denominada dependente, e uma ou mais variáveis, chamadas de independentes ou preditoras (HAIR et al., 2005).

Foram obtidas 444 respostas validas: $52 \%$ eram mulheres e $48 \%$ homens. Em relação à faixa etária, os respondentes foram divididos em quatro grupos: o primeiro grupo situado na faixa de até 27 anos (29\% da amostra); o segundo, entre 28 e 38 anos $(34,7 \%$ da amostra); o terceiro, entre 39 e 49 anos $(22,1 \%)$; o quarto, acima de 50 anos, representou apenas $14,2 \%$ dos respondentes. Com referência ao estado, grande parte dos respondentes $(70,7 \%)$ originou-se do estado de São Paulo. Os demais estados citados representaram $29,3 \%$ da amostra.

\subsection{Instrumentos}

De acordo com a soma das notas de cada afirmação contida no questionário, verificou-se que, das cinco afirmações com as maiores pontuações (melhores avaliações pelos consumidores), duas diziam respeito aos elementos da experiência de consumo e três estavam relacionadas ao conceito de qualidade do serviço. Esse aspecto ganha maior relevância se considerado que o número de afirmações relacionadas à experiência de consumo é menor do que o número de afirmações relacionadas à qualidade.

As afirmações relacionadas à experiência de consumo com as maiores pontuações diziam respeito à qualidade dos produtos e à localização da concessionária. Quanto à qualidade dos serviços, as afirmações mais bem pontuadas estão relacionadas ao fato de as concessionárias 
possuírem equipamentos modernos, instalações físicas atraentes e funcionários gentis.

Ao analisar as três afirmações relacionadas à qualidade dos serviços com as maiores pontuações, é possível verificar uma estreita relação entre os três com elementos do modelo de experiência de consumo proposto por Verhoef et al. (2009) e utilizado neste estudo: (1) a existência de equipamentos modernos possui relação direta com a tecnologia que compõe a interface do serviço no modelo da experiência de consumo; (2) as instalações físicas estão diretamente relacionadas com a atmosfera do varejo; (3) os funcionários gentis representam os funcionários em interface do serviço.

Um ponto a ser destacado relaciona-se ao preço, tanto na avaliação de promoções quanto no aspecto preços, os quais, conjuntamente, obtiveram as piores avaliações. Diante dessas pontuações, pode-se concluir que a imagem que os consumidores possuem das concessionárias de veículos em relação a preços $\mathrm{e}$ promoções não é boa e representa, assim, um aspecto importante a ser avaliado e gerenciado pelos varejistas do setor, uma vez que esse elemento foi classificado por Verhoef et al. (2009) como parte do conjunto de variáveis que compõe a experiência de consumo passível de ser controlado pelos varejistas.
Realizou-se, a seguir, uma análise de correlação das 25 variáveis que, de acordo com Stevenson (2001), tem por objetivo determinar a força do relacionamento entre duas observações emparelhadas. Com base nos valores obtidos por meio dessa análise, foi possível verificar que as afirmações que apresentaram maiores correlações com a afirmação 25 , que representa a satisfação dos consumidores dos serviços automotivos, objeto deste estudo, foram a Q21 ("Eu considero os serviços desta empresa de alta qualidade") e a Q20 (“Eu considero esta empresa muito confiável"), com $r$ de Pearson igual a 0,659 e 0,645 , respectivamente.

Essa constatação é de suma importância para este estudo, pois a partir dela é possível concluir que a experiência de consumo e a qualidade dos serviços podem ser consideradas fatores diretamente relacionados com a satisfação dos consumidores de serviços em concessionárias de veículos. Esse resultado vai de encontro à afirmação de Palmer (2010) de que os trabalhos acadêmicos estão começando a reconhecer a importância da experiência do cliente como um integrador da qualidade do serviço.

Com a intenção de verificar qual a influência dos elementos da experiência de consumo e dos atributos da qualidade dos 
serviços na satisfação dos consumidores de serviços automotivos, objetivo principal deste estudo, procedeu-se a uma análise de regressão multivariada, que, de acordo com Stevenson (2001), tem como objetivo estabelecer uma equação para predizer valores de uma variável dependente para os valores de diversas variáveis independentes. $0,094 R S E+0,0805 P S B+0,080 A T R+0,052 E P P$

Onde:

SAT $=$ Satisfação Global

SAQ $=$ Eu considero os serviços desta empresa de alta qualidade

$\mathrm{GTC}=$ Eu gostei de comprar nessa loja

$\mathrm{PBQ}=$ Os produtos eram de boa qualidade

$\mathrm{FRC}=$ Os funcionários responderam as perguntas com clareza

$\mathrm{RSE}=$ Eu recebi o serviço que esperava

$\mathrm{PSB}=$ Os preços eram muito bons

$\mathrm{ATR}=\mathrm{O}$ atendimento foi rápido

$\mathrm{EPP}=\mathrm{A}$ empresa entregou os serviços no prazo prometido

Dados adicionais do modelo escolhido:

$\mathrm{R}=0,821 ; \mathrm{R}^{2}=0,674 ; \mathrm{R}^{2}$ ajustado $=0,668^{3}$

Pela equação da satisfação obtida por meio da análise de regressão multivariada, foi possível comprovar o que talvez seja a maior contribuição deste estudo: os elementos da experiência de consumo e da qualidade dos serviços representam um papel de extrema

\subsection{Análise de Dados}

De acordo com os resultados obtidos por meio da análise de regressão multivariada dos dados, a experiência de consumo de serviços automotivos pode ser definida através da seguinte equação: 
significa o resultado da comparação que o cliente faz do serviço esperado com o serviço percebido. Ainda conforme esses autores, quando o serviço esperado é equivalente ao percebido, a qualidade percebida é satisfatória. Assim, demonstrase a importância que a variável "receber o serviço esperado" tem sobre a formação da satisfação do consumidor, importância essa percebida nesta pesquisa, uma vez que a afirmação concernente a essa variável também fez parte da composição da equação da satisfação.

A segunda afirmação de maior representatividade relaciona-se à imagem da loja e vem de encontro às contribuições de Puccinelli et al. (2009), que associaram a imagem da loja a aspectos da atmosfera, que foi um dos domínios de investigação do comportamento do consumidor que influenciam a experiência do cliente.

A qualidade do produto demonstrou ser, de acordo com a equação obtida, de grande importância para os consumidores de serviços de concessionárias de veículos, e essa afirmação está diretamente relacionada ao elemento sortimento da experiência de consumo, conforme modelo de Verhoef et al. (2009) utilizado nesta pesquisa.

Ainda de acordo com o autor acima citado, a experiência do cliente pode ser originária da interação entre cliente e produto. Além disso, o autor ressaltou que a variedade de produtos faz parte do conjunto de elementos que estão sob o controle do varejista. Desse modo, esse resultado demonstra uma situação que pode ser administrada pela gerência varejista com benefícios diretos na satisfação dos consumidores de serviços de concessionárias de veículos.

O papel do funcionário para a satisfação dos consumidores de serviços automotivos também demonstrou ser de grande importância. Esse aspecto foi discutido por vários autores como: (1) Dotchin e Oakland (1994), que afirmaram ser de grande importância o papel do empregado e sua conduta devido à presença do consumidor na produção do serviço; (2) Grewal, Levy e Kumar (2009), os quais verificaram que muitos varejistas estão percebendo o seu crescimento e sua rentabilidade como resultados determinados por coisas pequenas que fazem uma grande diferença na satisfação e na fidelização dos clientes como, por exemplo, facilitar a interação entre clientes e empresa e responder de modo adequado às necessidades do cliente (feedback).

A existência de bons preços está diretamente relacionada com a satisfação dos consumidores pesquisados. Para Bäckström e Johansson (2006), os preços contribuem, também, para a criação da experiência dos consumidores na loja. 
Outra afirmação importante na equação da satisfação do consumidor foi a rapidez no atendimento. A relevância da rapidez no atendimento foi relatada por Strombeck e Wakefield (2008) e Khauaja (2008). O estudo realizado por Strombeck e Wakefield (2008) demonstrou que a demora no atendimento pode fazer com que o consumidor não enxergue uma excelente prestação de serviço, ainda que o serviço tenha um desempenho excepcional. Khauaja (2008) afirmou que como o serviço em uma concessionária de veículos é realizado na hora, a rapidez torna-se um atributo importante.

Além da rapidez no atendimento, outra afirmação relacionada à qualidade do serviço e também à dimensão tempo foi considerada possuidora de um importante papel na satisfação dos consumidores: entregar o serviço no prazo prometido. Essa dimensão desempenha um papel importante em relação à qualidade dos serviços: no modelo de Parasuraman, Zeithaml e Berry (1985), a qualidade do serviço é mensurada comparando as expectativas com as percepções. $\mathrm{O}$ efeito do tempo é incorporado à avaliação final do serviço com base no seu impacto sobre a capacidade de resposta e acesso. A análise do impacto da duração na qualidade do serviço através da medição da diferença entre as percepções e as expectativas é provavelmente a análise mais comum encontrada na literatura e tem sido aperfeiçoada constantemente (BITRAN; FERRER; OLIVEIRA, 2008).

\section{CONSIDERAÇÕES FINAIS}

A confirmação de que os elementos diretamente ligados à qualidade dos serviços devem ser considerados detalhadamente na compreensão da experiência de consumo pode ser julgada a maior contribuição deste estudo à teoria da administração.

Nesse sentido, os resultados encontrados nesta investigação mostram as seguintes evidências: (1) os aspectos relacionados à experiência de consumo são de grande importância para a satisfação; (2) os aspectos relacionados à qualidade possuem grande relação com a experiência de consumo, além de desempenhar um importante papel na satisfação do consumidor.

Os resultados obtidos reforçaram a preocupação que guiou este estudo, a de evidenciar que a experiência de consumo depende do esforço da empresa em atender os aspectos compreendidos no modelo, mas também dos aspectos relacionados à qualidade do serviço, que se mostraram igualmente importantes na formação dessa experiência.

As principais contribuições deste estudo para a área acadêmica referem-se à 
necessidade de levar em conta, conjuntamente, os aspectos associados à experiência de consumo e as variáveis de qualidade de serviço. Em relação à área gerencial, fica evidente a necessidade de a empresa prestadora de serviços realizar com regularidade 0 treinamento/capacitação de seus funcionários no tocante à qualidade, mas também dedicar uma parcela importante de seu esforço aos aspectos associados à imagem da empresa, como decisão de localização, conjunto de produtos ofertados, equipamentos utilizados, layout, área de atendimento a clientes, entre outros.

$\mathrm{Na}$ realidade, a pesquisa evidenciou que os aspectos da qualidade dos serviços encontraram-se presentes na obtenção de uma maior satisfação do consumidor e estiveram em conformidade com o conceito de experiência de consumo. A grande contribuição do artigo foi o detalhamento dos aspectos relacionados à qualidade dos serviços (que não apareceu originalmente no modelo de experiência de consumo).

Uma limitação deste estudo se refere à amostra da pesquisa, selecionada por conveniência, o que pode restringe a capacidade de generalização dos resultados obtidos. Faz-se necessário ressaltar também que foi abordado apenas o segmento de concessionárias automotivas, representando, assim, outra limitação do estudo.

Os estudos realizados na área da qualidade ainda estão mais relacionados à área de produtos do que à área de serviços. O importante papel que a área de serviços vem desempenhando na economia mundial justifica que mais pesquisas na área de qualidade de serviços sejam desenvolvidas.

Neste estudo, o papel da experiência de consumo e da qualidade dos serviços focou a área de concessionárias automotivas. Estudos adicionais poderiam replicar a pesquisa em outras atividades de serviços.

\section{REFERÊNCIAS}

Associação Nacional dos Fabricantes de Veículos Automotores. Disponível em: $<$ http://www.anfavea.com.br $>$. Acesso em: 11 fev. 2009.

BÄCKSTRÖM, K.; JOHANSSON, U. Creating and consuming experiences in retail store environments: Comparing retailer and consumer perspectives, Journal of Retailing and Consumer Services, v. 13, p. 417-430, 2006.

Banco Nacional de Desenvolvimento Econômico e Social. O Novo Ciclo de Investimentos do Setor Automotivo Brasileiro, Informe Setorial, Área Industrial, n. 7, jul. 2008.

BEBER, S. J. N.; ROSSI, C. A. V. Estudo da Insatisfação do Consumidor nos Serviços Prestados por Assistências Técnicas Autorizadas de Automóveis, RAC - Revista de Administração Contemporânea, v. 10, n. 2, abr./jun. 2006. 
BERRY, L. L. Competing with quality service in good times and bad. Business Horizons, v. 52, p. 309-317, 2009.

BITRAN, G. R.; FERRER, J. C.; OLIVEIRA, P. R. Managing Customer Experiences: Perspectives on the Temporal Aspects of Service Encounters, Manufacturing \& Service Operations Management v. 10, n. 1, p. 61-83, 2008.

CARDOSO, R. N. An experimental study of consumer effort, expectation, and satisfaction. Journal of Marketing Reserch, v. 24, p. 244-249, 1965.

CHEN, C. N.; TING, S. C. A study using the grey system theory to evaluate the importance of various service quality factors. International Journal of Quality \& Reliability Management, v. 19, n. 7, p. 838-861, 2002.

CRONIN, J. J. JR.; BRADY, M. K.; HULT, G. T. M. Assessing the Effects of Quality, Value, and Customer Satisfaction on Consumer Behavioral Intentions in Service Environments. Journal of Retailing, v. 76, n. 2, p. 193-218, 2000.

CRONIN, J. J. JR.; TAYLOR, S. A. SERVPERF versus SERVQUAL; Reconciling performance-based and Perceptions-Minus-Expectations Measurement of Service Quality. Journal of Marketing; v. 58, n. 1, p. 125-131, jan. 1994.

DOTCHIN, J. A.; OAKLAND, J. S. Total Quality Management in Services - Part 2:

Service Quality. Internacional Journal of Quality \& Reliability Management, v. 11, n. 3, p. 27-42, 1994.

Federação Nacional da Distribuição de Veículos Automotores. Semestral da Distribuição de Veículos Automotores no Brasil. 2008. Disponível em: $<$ http://fenabrave.org.br $>$. Acesso em: 11 fev. 2009.
FINN, A.; KAYANDE, U. Scale modification: alternative approaches and their consequences. Journal of Retailing, v. 80, p. $37-52,2004$.

FITZSIMMONS, J. A.; FITZSIMMONS, M. J. Administração de Serviços Operações, Estratégia e Tecnologia de Informação. Tradução Gustavo Severo de Borba ... [et al.]. Porto Alegre: Bookman, 2000.

GENTILE, C.; SPILLER, N.; NOCI, G. How to Sustain the Customer Experience: An Overview of Experience Components that Co-create Value with the Customer, European Management Journal, v. 25, n. 5, p. 395-410, 2007.

GREWAL, D.; LEVY, M.; KUMAR, V. Customer Experience Management in Retailing: An Organizing Framework. Journal of Retailing, v. 85, n. 1, p. 1-14, 2009.

GRÖNROOS, C. Marketing services: the case of a missing product. Journal of Business \& Industrial Marketing, v. 13, n. 4/5, p. 322-338, 1998.

HAIR, JR., J. F. et al. Análise Multivariada de dados. Tradução Adonai Schlup Sant'Anna e Anselmo Chaves Neto. 5 ed. Porto Alegre: Bookman, 2005.

JONHSON, R. L.; TSIROS, M.; LANCIONI, R. A. Measuring service quality: a systems approach. Journal of Services Marketing, v. 9, n. 5, p. 6-19, 1995.

KHAUAJA, D. M. R. O Papel das Marcas na Construção de Relacionamentos entre Varejistas e Clientes. Disponível em: $<$ http://www.ead.fea.usp.br/Semead/10sem ead/sistema/resultado/trabalhosPDF/128.pd f>. Acesso em: 10 dez. 2008.

LADHARI, R. A review of twenty years of SERVQUAL research, International 
Journal of Quality and Service Sciences, v. 1, n. 2, p. 172-198, 2009.

\section{LAMBIN, J. J. Market-driven}

Management Strategic and Operational Marketing. Palgrave, 2000.

\section{LOVELOCK, C. Administración de} servicios. México: Pearson Education, 2004.

NUNES, W.; MARTINS, C. De quem é o mercado? Revista Mercado Automotivo, v. 221, 2013. Disponível em:

$<$ http://www.revistamercadoautomotivo.co m.br/Revista-Mercado-

Automotivo.php? $=23>$. Acesso em: 11 mar. 2014.

PALMER, A. Customer experience management: a critical review of an emerging idea, Journal of Services Marketing, v. 24, n. 3, p. 196-208, 2010.

PARASURAMAN, A.; ZEITHAML, V. A.; BERRY, L. L. A Conceptual Model of Service Quality and Its Implications for Future Research. Journal of Marketing, v. 49, n. 4, p. 41-50, 1985.

PARENTE, J. Varejo no Brasil. São Paulo: Atlas, 2000.

PARKER, C., MATHEWS, B. P. Customer satisfaction: contrasting academic and consumers' interpretations. Marketing Intelligence \& Planning, v. 19, n. 1, p. 38-44, 2001.

PIERITZ, O. Concessionárias de Automóveis: estratégias competitivas e relações de dependência com montadoras e bancos das montadoras. Revista de Negócios, v. 8, n. 4, 2003.

PINE II, B. J. La Economia de La Experiencia, Especial Gestion 15 Anos, 2010.

PIMENTA, L. J.; CRUZ, R. A Crise da Rede de Concessionárias de
Automóveis no Brasil. Disponível em: $<$ http://ftp.abradif.com.br/Informatica/Pim enta/ARTIGO.pdf>. Acesso em: 11 mar. 2014.

POPADIUK, S., MEINERT, C. R. A estratégia multimarcas como um fator de inovação em revenda de veículos novos.

Revista de Ciências da Administração, v. 9, n. 18, p. 80-104, 2007.

PUCCINELLI, N. M. et al. Customer Experience Management in Retailing: Understanding the Buying Process, Journal of Retailing, v. 85, n. 1, p. 15-30, 2009.

SHEWHART, W. A. Economic Control of Quality of Manufactured Product, Princeton, NJ, 1931.

STEVENSON, W. J. Estatística aplicada à administração. São Paulo: Harbra, 2001.

STROMBECK, S. D.; WAKEFIELD, K. L. Situational influences on service quality evaluations, Journal of Services

Marketing, v. 22, n. 5, p. 409-419, 2008.

TAN, K. C.; PAWITRA, T. A. Integrating SERVQUAL and Kano's model into QFD for service excellence development.

Managing Service Quality, v. 11, n. 6, p. 418-430. 2001.

TORRES Jr., N.; MIYAKE, D. I; PEREIRA, C. C. de P.; Proposta de um modelo de referência para a descrição do Processo de Desenvolvimento de Serviços. In: XIII SIMPÓSIO DE ENGENHARIA DE PRODUÇÃO, 2006, Bauru - SP, Anais eletrônicos... Bauru - São Paulo, 2006. Disponível em:

$<$ http://www.cepead.face.ufmg.br/files/nuc leos/nipe $\log /$ Artigo31.pdf $>$. Acesso em: 25 fev. 2009.

VARGO, S. L.; LUSCH, R. F. Evolving to a New Dominant Logic for Marketing. 
Journal of Marketing, v. 68, p. 1-17, 2004.

VERHOEF, K. et al. Customer Experience Creation: Determinants, Dynamics and Management Strategies. Journal of Retailing. v. 85, n. 1, p. 31-41, 2009.

YAN, B., MCLAREN, P. A. Measuring After-sales Service Quality in Automobile Retails: an Application of the SERVQUAL Instruments, Industrial Engineering and Engineering Management (IEEM), p. 2090-2094, 2010.

ZEITHAML, V. A. Service Quality, Profitability, and the Economic Worth of Customers: What We Know and What We Need to Learn. Journal of the Academy of Marketing Science, v. 28, n. 1, p. 6785, 2000.

Notas

${ }^{1}$ SHEWHART, W. A. Economic Control of Quality of Manufactured Product, Princeton, NJ, 1931.

${ }^{2}$ CARDOSO, R. N. An experimental study of consumer effort, expectation, and satisfaction. Journal of Marketing Reserch, v. 24, 1965, p. 244-249.

3 O valor de R2 ajustado pode ser considerado significativo, principalmente se levado em conta que se trata de uma aplicação voltada para ciências humanas. 